\title{
Research on Development and Future Potential of Healthy Food in China
}

\author{
Yixiao Chen ${ }^{1, \dagger}$, Qijian Lai ${ }^{2, *, \dagger}$, Yuxuan $\mathrm{Li}^{3, \dagger}$, Hanxin Zhang ${ }^{4, \dagger}$
}

\author{
${ }^{1}$ Wuhan Sannew School \\ ${ }^{2}$ Nutrition Department, University of California, Davis \\ ${ }^{3}$ College of Art \& Sciences, Syracuse University \\ ${ }^{4}$ College of Art \& Sciences, Syracuse University \\ *Corresponding author. Email: qijlai@ucdavis.edu \\ These authors contributed equally.
}

\begin{abstract}
With the development of society and economy, people pay more attention to the eating style, and healthy diet has become one of the hottest topics at present. This article mainly studies the Chinese health fast food market and analyzes the development trend of the market from different aspects. First of all, from the political and economic aspects, indicting that China advocates a healthy diet for all the people and the per capita income keeps growing. From a social point of view, people's attitudes towards healthy fast food also become positive with the increase of education level. As for technology, various new fresh-keeping technologies and the promotion of supply chain also provide a good foundation for the fast food industry. What's more, through the comparison of different companies and products at home and abroad, it is concluded that the characteristics of green food in China are different from those of other products, because China has different health needs and different ways of forming companies in the industry. Due to the lack of government regulation, consumers need to develop food awareness and form their own dietary decisions. With the development of new media, a new sales model comes into being, which creates a bigger sales platform for healthy fast food. The example of Shark Fit is introduced and analyzed to validate it. But for other healthy fast food start-ups, the biggest challenge is to establish a foothold in the competitive new media. Therefore, the healthy fast food industry in China still has huge potential for development.
\end{abstract}

Keywords: Healthy food, PEST, Product comparison, New media.

\section{INTRODUCTION}

As increasing per capita income level in China, Chinese's daily requirements shift to higher quality lifestyle. Among those requirements to achieve high quality lifestyle, the need for diet expanded from better flavor to healthier diet demands. With the development of new media, the ways that people gain information about food nutrition increase. People are attracted by the advertisement and new product and consume for healthier dietary pattern. After 2019, higher income level and greater flow of information on the internet finally lead to great concern and demand for healthy dietary pattern among Chinese.

The green food industry is growing in response to public demand. The continuous development of online new media has aided the formation of China's health food industry. New media not only push the development of health food industry, but also determine the direction of the development. The direction of new media indirectly and directly leads the customers to certain types of products. Most health food companies in China opt to alter their business model to maximize the profit from customer group in new media. Using new media to sell health food product is rare all over the world. In this way, the development of green food industry in China distinguishes from other countries.

Chinese companies learn the Chinese food market quicker than international food companies due to localized product design and localized company development model. However, the current market share is enduring because new media is not only open for Chinese companies. Other companies can mimic the business model of successful products or even 
successful companies. Then, when increasing brands and products get the same recommendation the advantage of new media is limited. Due to marginal effect, each investment in new media propaganda effect less than before. Due to the potential market of health food industry and reproducible properties of food products, more new companies want to enter the industry, enhancing the competition pressure. Some companies choose to predict the trends by developing new technology. Some companies choose to lead the trend by producing their own production line and set of star product. Some companies still invest and believe the power of new media. The following strategies of Chinese health food companies is vital.

Ortega et al. analyze Chinese consumers' concern surrounding food safety. It measures consumer preference on sources or attributes of pork by choice experience models. Furthermore, it combines the result from choice experience models with customers' food safety risk perception. It concludes that food safety risk concern influences customer preference. Chinese customers are willing to pay higher prices for food with certification. Although China has not formed a complete system, Chinese government certification earns the greatest trust, followed by the third-party certification, a traceability system, and a product-specific information level [1]. Liu et al. assess Chinese consumers' understanding and usage of the Chinese food nutrition label and their factors by a self-administered structured questionnaire conducted in Beijing and Baoding. The questionnaire covers objective and subjective questions on nutrition knowledge and collects data on participants' education level, age, familiarity with food nutrition labels, diet status and soci-demographic. It concludes that Chinese consumers have a moderate level of subjective understanding and low level of objective understanding on food nutrition labels. About $70 \%$ of participants claimed that they never use or seldom use nutrition labels. Also, objective and subjective nutrition knowledge and familiarity with food nutrition level have a positive effect on understanding and usage of food labels. Age has a negative relationship with both subjective and objective knowledge. Education level only has a positive relationship with objective knowledge [2].

Zhu et al. analyze the factors that determine green food consumption intention and consumption behavior from a sample of 457 Chinese consumers. It developed a conceptual model including the analysis of internal factors of consumers, external factors and context factors. As a result, although promotion can bring consumption intention, environmental value is vital for consumption accomplishment. Education as an internal factor determines green food consumption but family income is the key that pushes green food consumption intention into green food consumption behavior. Purchasing convenience as a context factor can push consumption intention into real consumption despite the fact that China has not built up a supply chain for purchasing convenience yet [3]. Divine and Lepisto analyze the healthy lifestyle consumer by examining demographic, personal value and psychographic antecedents to get a better understanding of these consumer in the whole market, they find out that female, older people, and high educated people tend to plan ahead and prefer more healthier lifestyle [4]. Osman et al. investigate the salient factors affecting convenient food consumption among working women. They use structural equation modeling to model working women's health awareness, price consideration, time factor, budget consideration and so on. They found that time factor has a significant positive impact on convenient food consumption. And the rest of factors do not have too much impact on the consumption of convenient food [5]. Glanz et al. use 2 self-administered cross-sectional surveys to examine personal dietary choices related to health and actually predict eating behavior. They found that taste is the most important factor that influences their food choice, the next one is the cost. Within a cluster of healthy lifestyle people, they prefer to pay much attention to nutrition and weight control when they choose what they eat [6]. Xiao indicates that a zero-sugar diet is a very effective diet plan for improving human health. It can help the body detoxify, balance hormone levels, and heal the liver. For people who want to lose weight, it can achieve rapid weight loss and reduce food cravings. According to the article, a zero-sugar diet requires a lot of whole foods, such as eggs, lean meat, and a moderate amount of sugar-free fat. Through a correct zero-sugar diet, the body can become stronger and more energetic. Xiao also provides different diet plans for readers with different dietary needs, such as the ultimate slimming dinner, super carnivorous dinner, and so on. These plans help readers develop a basic dietary concept and provide reference cases to allow readers to have a zero-sugar diet [7]. Buckleya et al. wrote a paper to report on the attitudes and reported behaviour of food consumers in Great Britain based on a review of their convenience food lifestyles. The paper also reports the development and application of a segmentation technique that can supply information on consumer attitudes towards convenience foods. The convenience food market in Great Britain is examined and the key drivers of growth in this market are highlighted. This paper studied a previous survey - A survey was applied to a nationally representative sample of 1000 consumers (defined as the persons primarily responsible for food shopping and cooking in the household) in Great Britain in 2002. Segmentation analysis, based on the identification of 20 convenience lifestyle factors, identified four CFL segments of consumers. The study provides an understanding of the lifestyles of food consumers in Great Britain, and provides food manufacturers with an 
insight into what motivates individuals to purchase convenience foods [8].

He reports the influence of the e-commerce network on contemporary enterprises. The e-commerce network platform serves as the main channel of communication for businesses; enterprises should make reasonable use of the network platform to build a good corporate image. The Internet has the advantage of rapid information dissemination, so with the help of the Internet, enterprises can obtain information and update their image in real time while releasing the latest corporate news to the public to proactively and timely shape the corporate image. Secondly, the network can increase companies' online interactions with customers to achieve the purpose of continuously improving brand image [9]. Alexandru reports that because of consumption changes of contemporary young people and changes in eating habits and requirements, the EU food market has decided to make changes to food in order to conform to the new consumption concept"light" food. Therefore, the EU market began to study the type, mixture, nutritional value, and commercial value of foods to gradually transform into a light food market. This highlights how a traditional, inelastic market has gradually become a consumer market [10]. Menrad wrote a paper about the market situation of Functional Food in Europe, and mainly discussed markets of functional food, suppliers of functional food and marketing of functional food. The method is to analyze some previous data, tables and graphs. The conclusion is functional Food offers interesting growth opportunities for the food industry but specific efforts of different actor groups are necessary to realize these opportunities in future. So far, multinational food industry companies as well as internationally acting food ingredient suppliers are best positioned to develop and market Functional Food. There are only limited opportunities for small and medium-sized companies in the Functional Food market. The market is characterised by a high rate of product failures [11]. Henderson and Kelly studied the type of foods advertised and nutritional claims made on the general market and African American programs were compared using $t$ and chi-squared tests. They mainly analyze 553 food advertisements appear- ing during 101.5 prime-time television hours. And the outcome measures is that advertisements were classified according to general category (fast-food restaurant, sit-down restaurant, packaged food), specific food type, and the presence of a weight-related nutritional claim. The result is more food advertisements appeared during African American programs than general market programs. These advertisements were more likely to be for fast food, candy, soda, or meat and less likely to be for cereals, grains and pasta, fruits and vegetables, dessert, or alcohol. Of all of the food advertisements, $14.9 \%$ made a weight-related nutritional claim. More claims related to fat content appeared during African American programming, whereas more light and lean claims appeared in general market advertisements. Their Conclusions and Implications are that practitioners and policy makers should be aware of the prevalence of food advertisements and their potential impact on knowledge and behavior and should consider working more closely with food manufacturers to encourage the creation and promotion of weight- friendly foods. Meanwhile, nutrition educators can help by teaching consumers critical thinking skills as may relate to food advertisements [12].

The research of this article revolves around healthy food. In today's society, healthy food has gradually become many people's focus to improve their quality of life. Many companies are investing in the research and development of health products and the promotion of health products, and new companies are established to tap into the newly developed health product market. The enormous attention the health food industry has attracted in such a short period is a topic worthy of exploring. In this article, we want to investigate the impacts of healthy food consumption and explore the advantages and disadvantages of healthy food on society, companies and individuals, to better understand the development and prospects of the healthy food sector in today's market.

\section{PEST ANALYSIS}

\subsection{Political}

In terms of national strategies and policies, some support has been given to the health fast food industry. Since the Fifth Plenary Session of the 18th CPC Central Committee put forward the "construction of a healthy China" as a national strategy and issued the "Healthy China 2030 Plan Outline", China's big health industry has witnessed rapid development in recent years. In response to the requirements of the central government, many sectors of society have transformed themselves into the health field.

Moreover, the National Health Commission also mentioned the need to promote the development of the convenience food industry with strict standards and healthy products. So the healthy fast food industry has been supported and encouraged by China.

\subsection{Economic}

When the People's republic of China was founded, per capita national income was only a few dozen dollars. As China's national income has risen rapidly in recent years, per capita national income has exceeded $\$ 10,000$ and people's lives have also been greatly improved. At the same time, people's consumption concept is also changing. Nowadays, when it comes to 
holidays, no matter the size of the restaurant, it is almost full, and it takes a long time to wait for a meal. However, a few decades ago, a meal in a restaurant was a luxury. Behind the booming restaurant business is the continuous improvement of people's living standards. With the development of economy, the improvement of living standards and the continuous improvement and upgrading of food supply system, the upgrading of consumption has become an inevitable trend; People no longer only pursue to eat fully, they began to pay more attention to the taste of food and whether it contains rich nutritional value; in order to meet demand, healthy fast food came into being. The healthy food developed by a professional team not only contains sufficient nutrients needed by the human body, but also has a delicious taste to meet the double needs of people. In addition, the COVID-19 outbreak in early 2020 sent Chinese citizens into quarantine at home for several months, so the "home economy" rapidly emerged, with the demand for fast food products surging. According to the data, Instant food is growing both online and offline, making it one of the top six annual food trends in 2020; Online channels, since February 2020, the overall sales volume of "Instant Fast Food" has increased by $700 \%$. Online shopping platforms such as Taobao and Jingdong have been out of stock, while offline sales channels such as stores have also seen the phenomenon of short supply. Healthy fast food as a part of fast food, in the era of "home economy", it is also a hot choice. According to the 2021 Insight Report on Instant Food Industry, women are the main consumers of Instant Food, and the generation born between 1985 and 2000 is the core driving group for the growth of the category. First-tier and second-tier cities are the main markets for instant food, while coastal provinces generally have a higher acceptance of the category.



Figure 1 MAT2018-2019 Convenient fast food market size and growth rate

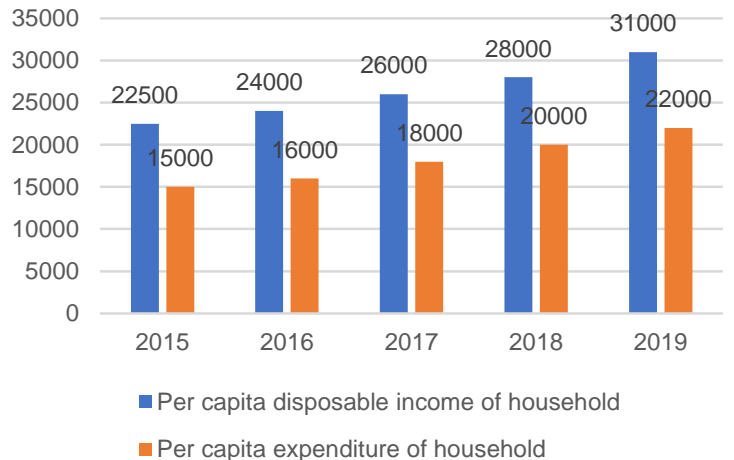

Figure 2 China's household disposable income and spending levels

\subsection{Social}

With the continuous improvement of the education level of Chinese people in recent years, people's attitude towards healthy fast food products have changed from the prejudice many years ago, such as "junk food" and "poor nutrition" to the acceptance in recent years. With the increase of education, young people begin to pay attention to the composition and nutritional value of food when choosing food. The ingredients and calories are listed on food packaging, and some foods contain additives in order to create a delicious taste, but some of the additives are not safe for humans. However, healthy fast food is different. Generally speaking, although the raw materials of healthy fast food are very simple, such as chicken, potatoes, beef and so on, the extra additives are strictly controlled and have strict nutrition distribution, so it is more popular with modern people. On the other hand, due to the rise of live broadcast products in China in the past two years, fast food products have successfully occupied a large proportion of the live broadcast products market due to their own product characteristics: convenient to carry and easy to store; In addition, nowadays people are in the fast-paced era, and they are not willing to spend 30-60 minutes cooking or waiting for takeout in the workday, so healthy fast food has become the best choice.

\subsection{Technical}

In terms of technology, health fast food companies are gradually increasing their product quality and production line in order to attract higher sales and people's attention.

\subsubsection{Continuous improvement of products}

First of all, from the point of view of the product itself, health has been greatly upgraded and guaranteed by reducing the fat content and calories. Health food brands, for example, the "TASTE LAB", in order to develop a type of zero sugar and protein chips called "High-protein Fish Chips", Team run out nearly two 
tonnes of tuna cost, with nearly a year, and after 30 times formula debugging, finally created a " 0 oil extruding technology". The team realized that using protein instead of starch. Each bag of "High-protein Fish Chips" has about $1 / 4$ of the $60 \mathrm{~g}$ calories of ordinary crisps. $100 \mathrm{~g}$ of fish crisps have more protein than 7 cups of milk or 5 eggs. Another example is the first product from "IMMI", "IMMI" is a brand of instant noodles, features low carbs and high protein. With 9 grams of net carbohydrates, 31 grams of protein and 9 grams of fiber per serving, the product have reduced carbs by nearly 75 percent and increased protein by five times compared to traditional instant noodles. Pumpkin seeds with protein and wheat gluten are the main components.

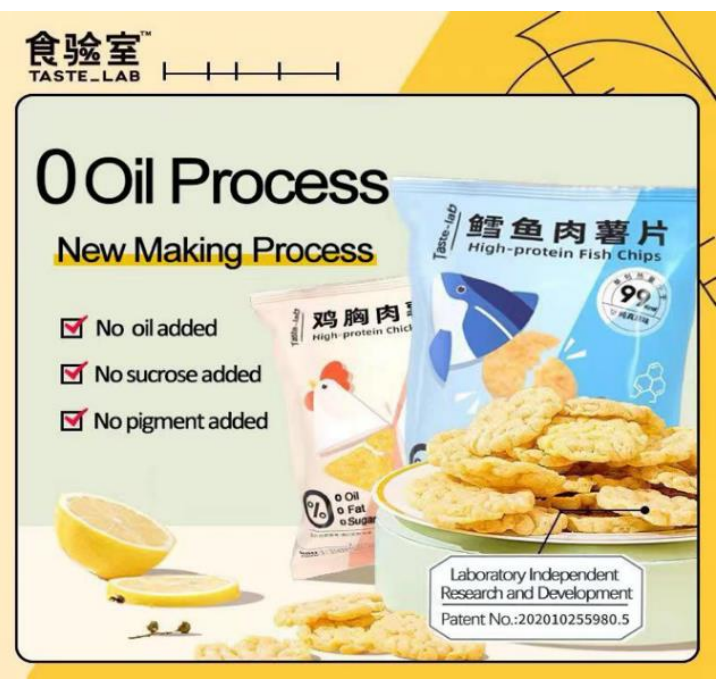

Figure 3 "0 oil technology" from "TASTE LAB"

While ensuring health, the taste of the product itself is often paid great attention to. "Chicken Breast" of "SharkFit" uses live chicken that has been killed within three hours to ensure its freshness and tender taste; "TASTE LAB" has developed many flavors people who want to try fish crips, such as lemon flavor and barbecue flavor.

Convenience of products has also been achieved to a new height. Many companies make the product can be eaten immediately when people open the package", which is aim to meet the needs of customers, like Shark Fit's chicken breast can be stored in room temperature and people don't need to warm up it.

\subsubsection{The promotion of supply chain}

Next, about the product supply chain. In order to ensure the quality of products, the "TASTE LAB", for instance, goes deep into the source supply chain during the research and development, builds a unified standard with the breeding base, and controls the supply of key raw materials. Tomato sauces, for example, traditional tomatoes do not tolerate high temperatures and will lose their original flavor after being roasted. Finally, the "TASTE LAB" found tomatoes in Xinjiang that had been exposed to sunlight for more than 12 hours. They dried and ground them in the sun, and eventually realized the mellow tomato flavor. Extreme supply chain efficiency provides a guarantee for the production chain of products. At present, it is known that the "TASTE LAB" has the control of the whole chain that is from raw material procurement to production and processing.

Moreover, it is so important for a brand to have a good product design and packaging. The brand "Genki Forest" uses unique color collision, let people in a short time to get the key information. Instead of a bright color, the outer packaging of "Genki Forest" is plain white, and each flavor will have a corresponding pattern. The bottle body is not a regular square bottle body, but a curved bottle body, not only easy to hold, but also from the bottle body recognition, forming a "brand impression".

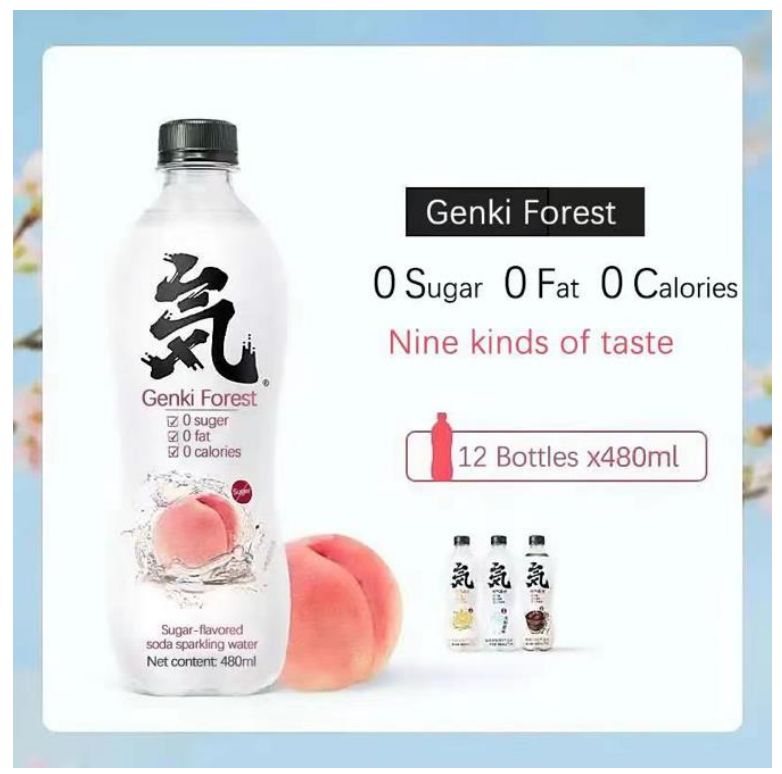

Figure 4 The design of a product from "Genki Forest"

\subsubsection{The consciousness of patent protection of healthy, fast food companies}

When healthy fast food companies have a rapid development, each company is particularly focused on patent to protect their own interests. "Genki Forest" has applied for a number of yoghurt-related patents. It is understood that "Genki Forest" has encountered from the beverage industry of the comprehensive copy. This company's officials have received hundreds of cases of counterfeiting involving more than 20 domestic beverage brands. Plagiarism involves copying everything, from raw materials and techniques to product brands, packaging and even marketing. So for this industry, patent application is a very important sector. 


\section{PRODUCT ANALYSIS}

\subsection{Product Comparison}

China domestic healthy beverages aims at three customer groups: the aged, urban youth and generation $\mathrm{Z}$ (age 15 to age 23). Among three groups, low sugar, low fat and low caloric are a new trend for customers. Low sugar for anti-aging contributed to the requirement for low sugar. Low fat and low caloric for low obesity concern contributed to the requirement for low fat and low caloric. Therefore, low sugar, low fat and low caloric are dominant characteristics for China domestic healthy beverages. Companies put effort into the innovation of beverages to retain the flavor and lower unhealthy contents. By replacing sugar with sugar substitute, the beverage does not belong to an unhealthy diet pattern anymore. This gives three customer groups stronger incentive to consume healthy beverages.

On the contrary, international healthy beverages want to target a greater customer population. Before China had the trend of low sugar, low fat and low caloric, international beverage companies detected the potential market for health beverages. In 2005, CocaCola exited Diet coke to meet consumer health needs. However, the sales of diet coke decreased over 15 years because sugar substitution did not satisfy the original flavor retention and health concerns of sugar substitution. Then, international companies focus on the healthy needs for preventing customers from chronic disease to grab a larger customer population. WHO recommends people to consume more fibers, less sugar and essential vitamins. So, in 2014, Coca-Cola purchased Schweppes and launched Schweppes C+ lemonade soda which a $300 \mathrm{ml}$ bottle soda can provide customers with $30 \%$ daily fiber needs. Also, Coca-Cola launched soda with fiber which provides customers with $30 \%$ daily fiber needs. Although Coca-Cola predicted the trends of healthy beverage, 2014 the trend of low sugar, low fat and low caloric has not started yet. Due to lack of marketing, these products have failed to impress the public with their low sugar characteristics. Until 2019, the development of China domestic healthy beverages matches the trend of low sugar, low fat and low caloric, China domestic healthy beverages are recognized as the healthy beverage and occupy the healthy beverage market. In 2020, the green beverage market will increase again after 2008. The increasing trend of green beverage product number shows the potential in the green beverage. Chinese companies capture the market due to the time difference. One of the domestic beverages, Genki Forest's revenue, achieved 2.9 billion in 2020. To achieve this, Genki Forest used six year from 2015. Although the revenue of Genki Forest is smaller than the revenue of Coca-Cola, as a 6year-old company, the speed of development is high.

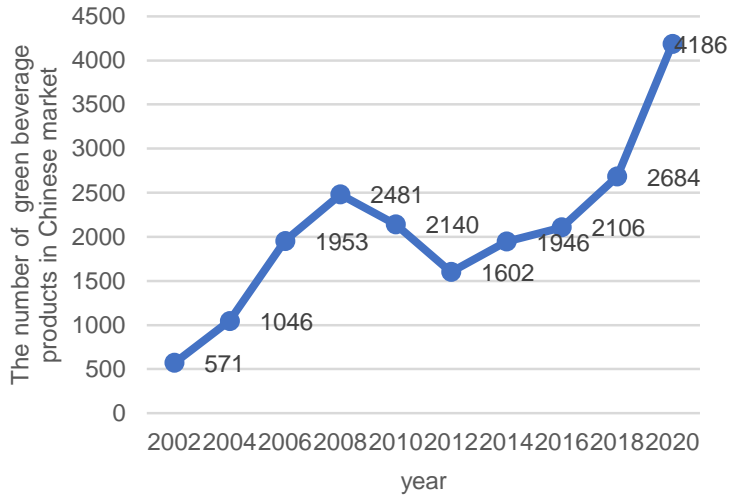

Figure 5 Trend of green beverage product number in Chinese market

\subsection{Company Comparison}

China's domestic food industry is developing. Small companies invest one star product of exclusive research and further increase market coverage. New companies will always want to develop new product categories to be distinct from existing companies. For example, for healthy snacks, small company develop their own technology such as deep-sea tuna chip with 0 oil puffing process. Thus, different companies dig into different food categories to occupy potential markets. In the long term, the innovation speed is fast, and the domestic categories are extensive. Among them, the most popular healthy staple food is meal replacement, which focuses on convenience and nutrition. The healthy staple food targets a wide range of customers. From an international perspective, healthy staple food is dominated by replacement shakes to achieve efficiency. Replacement shake lacks the flavor, so it is not suitable for Chinese customers in the long term. Chinese dietary pattern is diversified, simple products like replacement shakes from the international market cannot take advantage of their characteristics.

\subsection{Future Trend of Chinese Health Food Industry}

The problem of domestic products is lack of profession for both companies and customers. Healthy products are required to match other food consumption. In detailed, domestic meal substitutes cannot guarantee full power to replace dietary intake, and it is difficult to meet the dietary requirements of the obese and diabetic population. Currently, the customers do not have enough knowledge to judge the quality of products. For subjective knowledge, customers' nutritional knowledge and ability of reading food nutrition labeling is low (Liu, 2015). 70\% of customers seldom use food nutrition labels for dietary decisions. This causes them to highly rely on advertising and misleading information. Consumers go through food safety 
problems and highly believe in government regulation (Ortega, 2011). However, in China, regulations on the health food industry have not formed yet.

International products on meal replacement can target the obesity and diabetes population because the social environment cares about chronic disease. The government and nutritionists will update dietary recommendations according to the latest scientific finding and population health trend each five year. This not only reminds people to eat healthier, but also teaches people how to eat healthier. Social nutrition education and dietary awareness enhance in the long term. Different from international customers, Chinese customers have their own objective view on health dietary patterns. The reliability of their own objective view has a positive relationship with education level, income level and age. Chinese traditional food patterns prefer heavy oil or salt so it's hard for the government to alter dietary patterns by regulation or recommendation. Customers need to enhance awareness. Green food companies should also take the responsibility for passing correct nutrition knowledge and dietary decisions to customers.

\section{PROMOTION OF NEW MEDIA}

\subsection{Definition and characteristics}

New media, as a new channel and mode of information transmission, not only makes people's daily life more convenient and efficient, but also becomes an important way for companies and enterprises to promote products and corporate images. New media software such as TikTok, Xiaohongshu, and Kuaishou provide platforms for companies to select appropriate media channels to promote products and companies. In addition, the new media apps provide a platform for media people to shoot and publish videos, which then attracts the public to download the software and spend time browsing the published videos. When media people have built a decent fan base and become key opinion leaders (KOLs), they can connect with different companies for product promotion and collect advertising fees. Some companies also register their official accounts on different platforms and then release marketing videos of their products. Live streaming, as a new way of new media sales, also contributes to product sales and the promotion of popular products. Because of the use of KOLs, company accounts, and live streaming, a company's products can attract the public's attention, so as to achieve the purpose of promoting products and the company.

Rapid production of popular products, cheap cost, openness, and globality are all features of new media. Frequent product showing first enhances people's impression, and using people's trusted media for publicity can increase their trust in the product.
Therefore, people will be more willing to purchase the product. Since network promotion is unbounded by regions, this mode can reach a greater number of audience and allow a large quantity of products to be sold in a short time, thereby developing the company's featured products. This mode is also less costly, in terms of money, time, space, and resources. Manpower and the need to maintain physical stores are significantly reduced, and money can be invested in product development and network promotion. On the new media platform, people can make purchases anytime and anywhere, which greatly saves the company's human resources, and the company only needs to carry out unified delivery of ordered products. Regarding globality, the circulation of the network allows enterprises to quickly reach various regions, and more sales regions mean more profits and larger consumer groups. Altogether, new media has the advantages of quick circulation, strong popularity, and rapid development of popular products.

\subsection{SharkFit product}

When it comes to promotion with new media, newly founded companies are especially good at using this method. SharkFit is a good example. SharkFit, an innovative enterprise focusing on the research and development and sales of light, healthy food, was founded by Xiaoming Qiang in 2017. Different from other contemporary young entrepreneurs, Qiang had rich experience in e-commerce operation and strong brand operation ability before founding SharkFit. Specifically, Qiang provided e-commerce consulting services for DaoxiangCun, WuFangZhai, and other big brands, and successfully started an online food ecommerce agent operation company with a total transaction amount of more than one billion yuan. Qiang has keen awareness of e-commerce trends. He noticed that Generation Z (i.e., people born between 1995 and 2009) have the most spending power, and when this age group purchases food, convenience is prioritized over health and taste. Given the rising awareness in health, it is the best time for new domestic brands to rise. As a result, SharkFit caters its products mainly for this group. This keen audience knowledge helps the company build a loyal customer base and maximize profitability. SharkFit has a tight hold on the public domain, private domain, and business domain traffic and ensures that all three traffic types are balanced. SharkFit sees customer experience and after-sales care as important means of increasing traffic and improving client conversion rates. Its portal offers a variety of products and rates. Since the opening of the Tmall store, SharkFit's sales have entered a period of rapid growth, with monthly sales exceeding five million in almost eight months. At present, there are more than 500,000 monthly orders on platforms such as JD.com, Tmall, and Pinduoduo, and SharkFit has achieved the top sales volume across all 
networks. On Tiktok, Station B, Xiaohongshu, and Taobao Live, SharkFit accelerates brand building and product visibility through graphics, short videos, and live broadcasts [13]. Although the company has just been established for four years, through the publicity of the new media platform, SharkFit has quickly achieved a good sales volume in the market. Specifically, SharkFit's most popular product, instant chicken breast, enables consumers to quickly build trust in the brand. Since chicken breast is an icon of healthy eating, the company's image as a healthy food provider has been established and popularized. Furthermore, the company's focus on traffic is a key factor of its success. SharkFit has access to free traffic, search traffic, and content traffic across all platforms. After mastering the advantages of traffic, SharkFit designs specific publicity focuses for different platforms. In Tianmao, for example, the core is the base of sales, in Jingdong, Jingdong logistics, and in Pinduoduo, the activity of billions of subsidies. Since the focus of each platform is different, SharkFit's conversion can increase its efficiency and create popular products. As of now, SharkFit has created more than ten popular products, and such success, according to Dong, can be attributed to SharFit's ability to analyze data from the entire network, achieve efficient drainage, and snatch strong back-end storage capabilities [13].

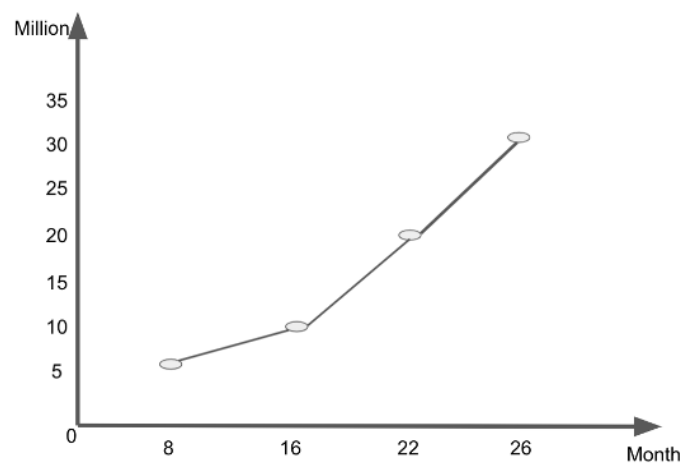

Figure 6 Accumulated sales quota of SharkFit

\subsection{Challenge}

Although a large number of companies have begun to pay attention to the new media marketing method with the hope to achieve good sales and branding results like SharkFit has done, the challenges associated with this tool need to be addressed. As more companies begin to invest in new media platforms, competition increases. Because of competition, some companies will face the risk of losing their stable sales quota or even failing to meet sales quota. In SharkFit's case, the best way to solve this problem is to create a flow-based health bloggers to help the company promote products. The second solution is to invest in research and development of new products to create unique products. Attracting the attention of the public with new products and expanding consumer groups through the use of traffic bloggers will help the company create a higher turnover rate in the future. In the new media era, effective use of media resources and dealing with challenges are the best practices for a company to grow in the long run.

\section{CONCLUSION}

This article analyzes government policies, the impact of economy and society on healthy fast food industry, and technological progress. Comparing the different characteristics of healthy products in China and abroad, the development of new media and its impact on the industry. It can be concluded that, firstly, the future of the industry is hopeful. The economic and social environment, such as coronavirus pandemic, is favorable for the industry. In addition, the support of new media makes healthy fast food get better and more comprehensive promotion. The general problem for companies is that they have high sales volume but do not earn profits, since they spend too much money on new media to attract costumers. The problem for costumers is the industry lacks government management. Therefore, costumers need to improve their knowledge and make rational purchase. Secondly, the difference between domestic and foreign products is because China's need to adapt its strategies to the environment, resulting in both positive and negative effects.

\section{REFERENCES}

[1] Ortega, D. L., Wang, H. H., Wu, L., \& Olynk, N. J. (2011). Modeling heterogeneity in consumer preferences for select food safety attributes in China. Food Policy, 36(2), 318-324.

[2] Liu, R., Hoefkens, C., \& Verbeke, W. (2015). Chinese consumers' understanding and use of a food nutrition label and their determinants. Food Quality and Preference, 41, 103-111.

[3] Zhu, Q., Li, Y., Geng, Y., \& Qi, Y. (2013). Green food consumption intention, behaviors and influencing factors among Chinese consumers. Food Quality and Preference, 28(1), 279-286.

[4] Divine, R. L., \& Lepisto, L. (2005). Analysis of the healthy lifestyle consumer. Journal of Consumer Marketing, 22(5), 275-283.

[5] Osman, I., Osman, S., Mokhtar, I., Setapa, F., Shukor, S. A. M., \& Temyati, Z. (2014). Family Food Consumpt

[6] Osman, I., Osman, S., Mokhtar, I., Setapa, F., Shukor, S. A. M., \& Temyati, Z. (2014). Family Food Consumption: Desire towards Convenient Food Products. Procedia - Social and Behavioral Sciences, 121, 223-231. 
[7] Xiao, L. (2017). Zero sugar? Zero problem: Bring balance to your diet in 2017 with these amazingly low-sugar, high-fiber, super delicious musclefriendly meals. Weider Publications LLC.

[8] Marie Buckleya, Cathal Cowan, Mary McCarthy. (2007) .The convenience food market in Great Britain: Convenience food lifestyle (CFL) segments. Appetite $49600-617$

[9] He, H. (2014). Shaping the Image of the Enterprise in the E-Commerce Network's Times. Applied Mechanics and Materials, 1641-1644.

[10] Burda, A. (2014). Development Solutions for the EU Food Market: Fucntional Foods. Knowledge Horizons - Economics, 6(4), 14-16.

[11] Klaus Menrad. (2003). Market and marketing of functional food in Europe. Journal of Food Engineering 56 (2003) 181-188

[12] VANI R. HENDERSON, MS; BRIDGET KELLY, MPH. Food Advertising in the Age of Obesity: Content Analysis of Food Advertising on General Market and African American Television. RESEARCH BRIEF

[13] Dong, Q, Y. (2020, September 27). SharkFit Xiaoming Qiang: E-commerce era, with the concept of convenience and health to redo the traditional just need diet WISE2020 E-commerce Industry New Ecology Summit. 36Kr. https://www.36kr.com/p/898473529176832 